\title{
Fuzzy Grading for Content Management in E-Learning Systems
}

\author{
Neeraj Kharya \\ Senior Lecturer, Department of \\ Computer Applications \\ Bhilai Insitutute of Technology \\ Bhilai House,Durg (Chhattisgarh)
}

\author{
Sanjay Sharma \\ Associate Professor, Department of \\ Applied Mathematics \\ Bhilai Insitutute of Technology \\ Bhilai House,Durg (Chhattisgarh)
}

\author{
Ani Thomas \\ Reader, Department of Computer \\ Applications \\ Bhilai Insitutute of Technology \\ Bhilai House,Durg (Chhattisgarh)
}

\begin{abstract}
The authors are motivated by the concept of refinement in elearning systems so as to provide more support for the e-learners. A technique has been proposed for providing a customized knowledge in the form of graphics, text, analogy etc by grading mechanism using fuzzy techniques through which the knowledge level of user or learner can be determined and enhanced. It is impossible to satisfy every learner with a single example, so there arises the need of a system which would take feedback from the learner and dynamically customize the learning materials as per the understanding level of the end-user or learner. The content Management Tool (CMT) of the proposed framework of Expert E- Tutoring system plays a vital role for extracting the required contents from content repository by making use of fuzzy techniques. The proposed framework may also keep track of users' learning capability based on fuzzy grading on a given topic, which helps to refine the e-learning content appropriately for the use of a learner.
\end{abstract}

\section{Categories and Subject Descriptors \\ I.2.6 [Learning K.3.2.]: Concept Learning}

\section{General Terms}

Management, Performance, Design, Reliability

\section{Keywords}

Content Management tool, Knowledge Management, E-Tutoring, Fuzzy Grading, Content Customization

\section{INTRODUCTION}

The pedagogy of on-line learning is still in it innovations, but it is already a useful tool and, if used well, can increase the range and excitement of learning. The differences between Face-to-face and purely web based courses are rapidly disappearing. The author focus on providing the customized study materials to the learner based on his/her learning and grasping caliber on the subject matter by making use of fuzzy techniques. E-learning is defined by many people, in many ways, and it is most important to gain the clear understanding of what e-learning is, with respect to this paper the most appropriate definition is: "E-learning provides the potential to provide the right information to the right people at the right times and places using the right medium". The efficiency of e-learning can be improved by introducing intelligence into e-learning environment by inculcating a feature for feedback and customization of web based e-learning material so that it will be at par of the learning capability of the learner.

Till date, the e-learning is assumed to be an asynchronous activity, where the web contents with appropriate examples, diagrams, pictorial representations, analogy etc are used in order to make subject materials clear the learner/reader. The idea is that the participants/learner may engage in exchange of ideas and information without the dependency of the content holder/Tutor involvement at the same time. This paper aims to provide the refined web-based content depending upon the learner's of various background and capability

\section{MOTIVATION}

Mohamed et al [1] , have proposed a e-learning system in which the learners is asked: where he or she fails to understand the learning materials. A set of expected questions and their answers is stored in the database. By making use of Latent Semantic Analysis (LSA) of questions are fired by the learner and compared with the saved questions in the database, whose semantic closeness is calculated by use of LSA. When LSA does not found exactly the same question saved in the database, the system uses other techniques. It proceeds to a refinement treatment of the collected question when LSA could not give an accurate decision. This treatment uses the meta data introduce by the tutors who have saved the questions and their answers. Every saved question has been answered only one time when it first has been asked. The learning steps prior to the stages described here has not been explored which motivated the authors to propose a complete frame work for the expert e-tutoring system.

\section{LEVEL OF KNOWLEDGE: THE LEARNER}

It is always not possible to have exactly same level and at same level, same number of examples available to convince the user communities with provided materials. So content management tool plays an important role here by retrieving the next best suitable example from the stored database either from the same level (if available) or from next level to refresh and customize the web content again to the user. 
Content management tool can select the next best suitable example based on the various parameters that can be based on the frequency of example that are accepted by the specified user community or based on the pre-determined (using fuzzy technique) level of user grading, which is discussed in our next section

\subsection{Knowledge Management}

Management is the key to the success of the proposed system. Through Knowledge management the efficiency of the system is improved widely because the theme is to provide the right information in the form of examples, analogy, graphs, statistics etc to the right person as per the understanding level and that too in right time without going to the irrelevant materials not for his or her use. With respect to our concept, Knowledge Management can be defined as "The systematic approach for the selection of contents with the help of content Management Tool (Figure 1) so as to regenerate the learning material from its knowledge assets." While discussing e-learning, it had been found that knowledge management plays an important role because Leaning and Knowledge management share a similar focus: How to enhance human knowledge. Both Learning and knowledge Management are looking for ways to categorize and store knowledge.

\section{EXPERT E-TUTORING SYSTEM}

The functionalities of Expert E-tutoring system are distinct from the more conventional approaches. The functionalities requires Expert E-tutoring system to generate instruction in real time, on demand as required by the individual learner. Furthermore, Expert E-tutoring system must support dialogue or discussion between the technology and the user. The goal of this tool is to provide support the content of the subject with example, analogy, pictorial representation, graphs etc on the subject topic so that it will be understandable to the learner. It is a fact that the grasping and understanding power will differ from person to person. Content at a glance will be readily understood by one person but the same will not be with the case with another person belonging to the same category. It might be possible that he needs some more assistance or some more supporting examples to make the content clear. For this we have to refine our subject materials and Provide it with more support with real world analogy, graphs etc by maintain some certain level of refinement.

An Expert tutoring system is a system that provides direct customized content as per the feedback given by the learner without the intervention of human beings. In this there can be a

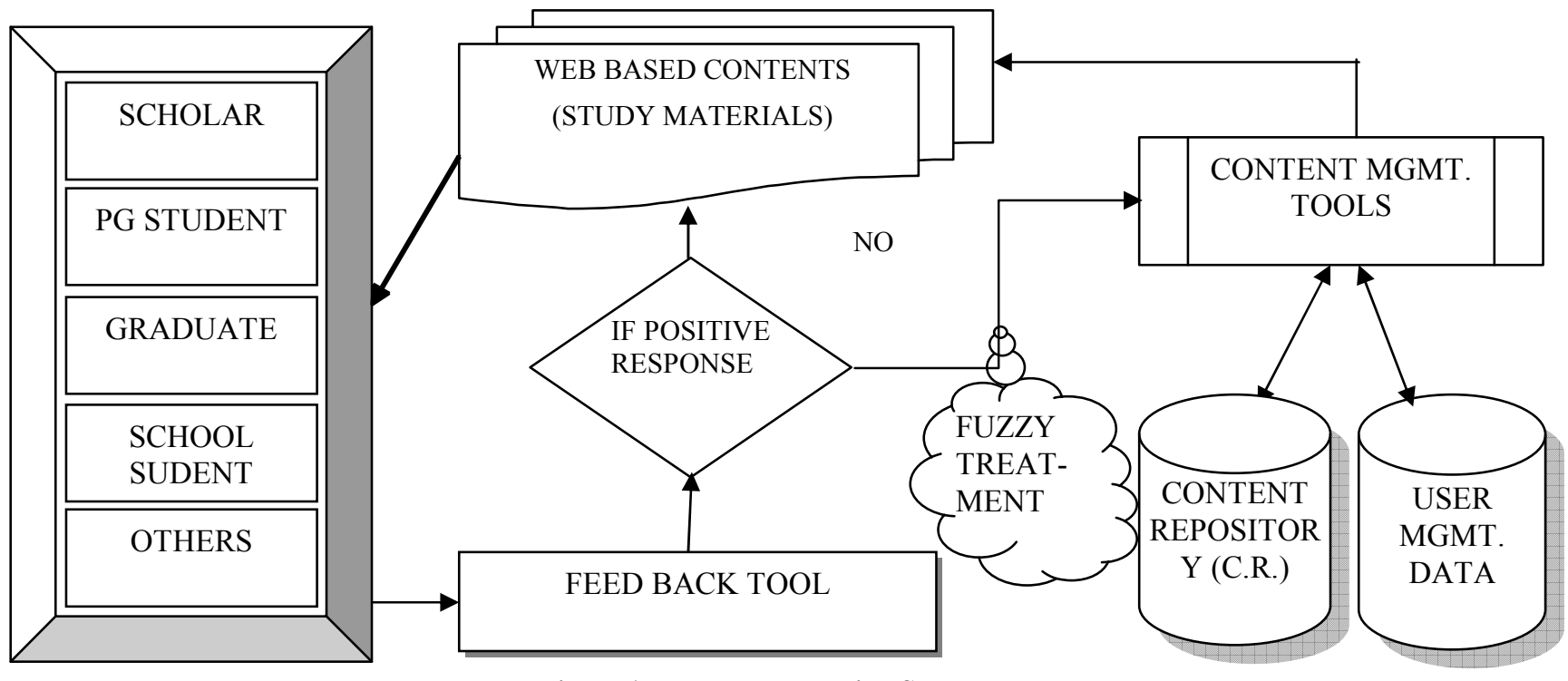

Figure 1: Expert E- Tutoring System

As discussed that there can be more than one example and other supporting materials are available in content repository but effective and efficient handling of content play a vital role. Which example and in which sequence and order question still unhandled till now? So, in this paper we suggest a technique which will not only grade the examples on the basis of their general acceptability but also by self learning module it will time to time update and customize the standard learning materials (a material with highest acceptability grade will become standard material). Moreover the standard material is not same for all the user community it will differ from learner background/knowledge level. wide category of user who want to surf the material and they are classified viz) Scholar, PG Student, Graduates, Teenagers etc. This people go through the web based multimedia contents and provide a feedback regarding the acceptability of material as per their learning and grasping caliber though FEED-BACK TOOL. Based on their feedback the next strategy is designed. If they come with a positive response the learning materials are refreshed and provide with next materials else if not, the web based contents are then customized using Content Management Tool (CMT).

The work of CMT is to retrieve the best example and related documents viz) graphs, analogy etc, from the stored database based on the ranking that had been decided by the fuzzy treatment and refresh the present the web content again to the 
learner. This process will go over and over until the learner will give the positive response or all the examples and supporting documents were get exhausted in order to satisfy the learner.

\section{FUZZY GRADING OF USER COMMUNITY}

Till now, it is proposed that fuzzy grading tool can be a part of the content management tool, whose work is to grade the knowledge level of the user logged - in (if previous record of his/her is available with database at User Management Data) by comparing how quickly with minimum feedback he/she will be able to understand the standard materials uploaded in e-learning. Based on the grading too, the content management tool can retrieve the content suitable in the form of table, analogy and other low-level of examples from the stored database and refresh the e-learning materials in order to convince the learner at the first attempt itself which saves the time and effort too.

\subsection{User Management}

It is proposed that each and every user, logged in to the e-learning session, will have an entry in the User Management database. The purpose of this Database is keeping the track of intelligence level of user on that subject topic. The users are graded on the basis of their intelligence and grasping and learning caliber in the scale of Poor, Average, Good, Very Good, and Excellent. Once the level of the User is decided by using fuzzy technique, this will help the application for customization of the web-content to be continued in the same session as well as for the customization of the webcontent for the future interaction with the same or with other subject materials

\section{EXPERIMENTAL SET-UP}

We can illustrate the working Expert E-tutoring system concept of e-learning with an example Jack, a person surfing the web based content for subject of his interest. If he is satisfied with the subject materials and examples discussed in the materials, He gave a positive response and continues with the other materials. With his corresponding response for the materials, his intelligence level is graded by the fuzzy system at the one end. At the other end, if he is not satisfied with the content materials discussed on the page, he give a response appropriately, and based on his response a web-page is dynamically refreshed with a new examples and analogy. At the back-end the content repository is crawled. The new contents for him are so chosen on the basis of fuzzy grading of examples which matches the intelligence level of Jack. Making repeated iteration of negative responses, still he is not satisfied with the contents uploaded through the content repository; at last what comes in a picture is the Latent semantic analyzer, which calculates the closeness between the current student's questions with the question that was saved in the database.

\section{CONCLUSION}

The authors present a concept of adaptive e-learning with an expert e-tutoring system. The primary need for e-learning is to provide maximum knowledge within the minimum time as possible. The paper proposes a mechanism, which will not only make an intelligent assessment about the knowledge level of the learner but also provide them with the right content and materials so as to satisfy their ends without going through the materials which are not of their use. The expert e-tutoring system will not only grade the intelligence level of the user community logged into the system but also perform knowledge management technique through which we can provide "right information to the right people at the right time" and thus portray the real intention with these added features.

\section{ACKNOWLEDGMENTS}

The authors wish their heart felt gratitude to the Management, Bhilai Institute of Technology - Durg, India for their inspiring encouragement a support towards the completion of the work.

\section{REFERENCES}

[1] Mohamed Jemni \& Issam Ben Ali : Automatic answering tool for e-learning environment, International Conference on Mumtimedia and ICT in Education, 22-24 April 2009, Lisbon, Portugal.

[2] Enrique Alfonscea, Rosa M. Carro, Manuel Freire, Alvaro Ortigosa, Diana Perez and Pilar Rodriguez : Authoring of Adaptive Computer Assisted Assessment of Free Text Answering, International Forum of Educational Technology \& Society (IFETS), 8(3), 53-65

[3] H. Chorfi \& M. Jemni, PERSO: Towards an adaptative elearning system, Journal of Interactive Learning Research, (2004), 15 (4), pp 433-447.

[4] Carro, R. M., Pulido, E., \& Rodríguez, P. (1999). Dynamic generation of adaptive internet-based courses.

Journal of Network and Computer Applications, 22 (4), 249257.

[5] Cristea, D., \& Tuduce, R. (2004). Test authoring for intelligent e-learning environments. Paper presented at the 1st International Workshop Authoring of adaptive and adaptable educational hypermedia at the Web-Based Education Conference (WBE), February 16-18, 2004, Innsbruck, Austria.

[6] Carro, R. M., Pulido, E., \& Rodríguez, P. (2002). Developing and accessing adaptive Internet-based courses. In L. C. Jain, R. J. Howlett, N. S. Ichalkaranje, \& G. Tonfoni (Eds.), Virtual Environments for Teaching and Learning, World Scientific Publishing Company, 111-149 